\title{
Symmetry is its own reward: on the character and significance of Acheulean handaxe symmetry in the Middle Pleistocene
}

\author{
Mark White $^{1, *} \&$ Frederick Foulds ${ }^{1}$
}

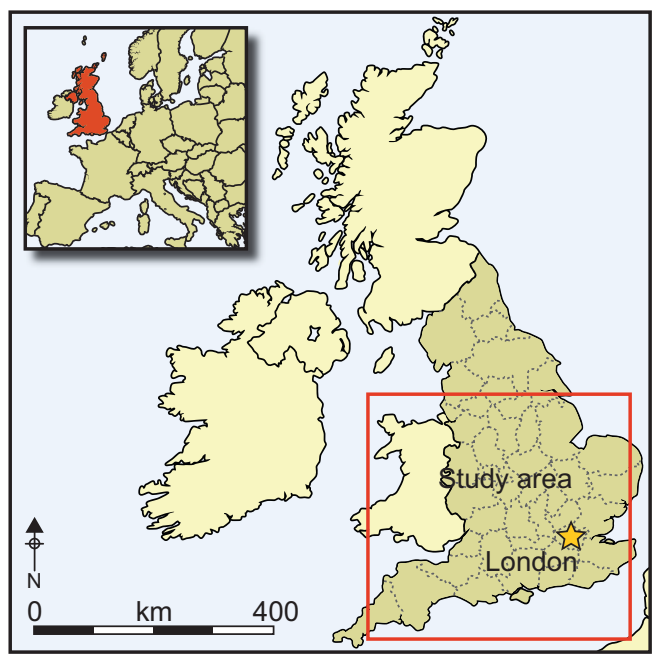

Bilateral symmetry in handaxes has significant implications for hominin cognitive and socio-behavioural evolution. Here the authors show that high levels of symmetry occur in the British Late Middle Pleistocene Acheulean, which they consider to be a deliberate, socially mediated act. Furthermore, they argue that lithic technology in general, and handaxes in particular, were part of a pleasure-reward system linked to dopamine-releasing neurons in the brain. Making handaxes made Acheulean hominins happy, and one particularly pleasing property was symmetry.

Keywords: Great Britain, Palaeolithic, handaxes, symmetry, pleasure-reward

\section{Introduction}

Handaxes are the definitive tool of the Acheulean techno-complex, made by at least three species of Homo over $\sim 1.4$ million years, and across much of Africa and Eurasia. Their predominantly oval- or pear-shaped planform, sharp cutting edge, bifacial working and symmetrical outline make handaxes the most distinctive tools of the Palaeolithic period, even though, as a class, they are remarkably variable. Two aspects of handaxe morphology have attracted special attention: variation/standardisation in shape and the degree of bilateral symmetry (where the shape of one edge mirrors that of the other). Both have been used to promote a range of cognitive, functional, technological, aesthetic, symbolic and social explanations, although with little consensus. Yet, while there are many detailed

\footnotetext{
1 Department of Archaeology, Durham University, South Road, Durham DH1 3LE, UK

* Author for correspondence (Email: mark.white@durham.ac.uk)
} 
studies of handaxe shape (e.g. Roe 1968; Issac 1977; McPherron 1994; White 1998a), similar considerations of symmetry are rare. In fact, there is no proper understanding of the frequency of highly symmetrical handaxes and no agreement on how to measure it. Current interpretations are thus based on anecdotal evidence (cf. Nowell in Wynn 2002; Schoenemann in Wynn 2002), on methods that produce idiosyncratic results that may underestimate symmetry (e.g. McNabb et al. 2004; cf. Underhill 2007; Hodgson 2015), or on large but curious samples (e.g. Cole 2015). In short, we lack a coherent dataset for studying Lower Palaeolithic handaxe symmetry, and consequently cannot properly address the factors that may be facilitating, creating or preventing it.

Two questions need resolving:

1) What is the frequency of highly symmetrical handaxes, and what might this reveal about the people who made them?

2) Does handaxe symmetry increase through time, perhaps demonstrating evolving cognitive structures and social intelligence in archaic Homo?

We present data addressing the first of these questions and offer a novel explanation for both symmetry and the apparent 'tyranny of the handaxe' in the Lower Palaeolithic world.

\section{Explaining handaxe symmetry}

Sensitivity to symmetry is a fundamental element of mammalian visual perception, hardwired and controlled by an automatically functioning brain network residing in the medial occipital gyrus (Hodgson 2009). In humans, it forms part of a package of core geometrical concepts that emerges at the age of about four months. From an evolutionary perspective, this may reflect that biologically important objects (such as people, predators and prey) are symmetrical, making symmetry perception a key discriminatory tool for processing visual information and, thus, vital for survival (Wynn 2002; Hodgson 2009).

Yet, while symmetry may be evident in the pattern-recognition mechanisms of animals in general (and ubiquitous in the natural world), it was only with the emergence of hominins of the Homo erectus grade and the Acheulean techno-complex $(\sim 1.75 \mathrm{ma})$ that humans began to impose symmetry (and shape) artificially onto stone tools, in the form of handaxes. It is the imposition of form onto the world, rather than simply perceiving it in the world, that constitutes for Wynn $(1995,2002)$ a cognitive leap, especially in shape recognition (symmetry, mirroring) and spatial thinking (the knapping process). The putative increased levels of symmetry after $500 \mathrm{ka}$, when it is found not only in plan-view but also more commonly in side- and end-views, marks another cognitive milestone that saw the development of modern Euclidian understandings and manipulations of shape and space (Wynn 2002: 402). By this point, hominins were also able to manipulate symmetry intentionally in other ways, sometimes deliberately violating it by creating twisted edges - as commonly found at Marine Isotope Stage (MIS) $11(\sim 424-374 \mathrm{ka})$ sites in Britain (White 1998b).

Despite these insights, there is little agreement on either the significance of handaxe symmetry or on its nature and frequency. Studies demonstrating increasing symmetry through time are virtually absent. Based on just 44 handaxes from three sites in Israel spanning 1.4 to $\sim 0.3 \mathrm{ma}$, Saragusti et al. (1998) concluded that levels of symmetry did 
increase through time, although the later addition of 124 younger handaxes from Tabun complicated the picture (Saragusti et al. 2005). Research on the Early Acheulean at Konso, Ethiopia, similarly detected increased symmetry through time (Beyene et al. 2013), but others doubt whether many handaxes-particularly earlier examples-are symmetrical at all. According to McNabb et al. (2004; Sinclair \& McNabb 2005), the handaxes from the Early Stone Age site of the Cave of Hearths in South Africa were rarely symmetrical and only minimally shaped to bring out core functional properties and regularise the midline. The Early Stone Age showed only "an incipient awareness of symmetry" (McNabb et al. 2004: 662).

Where a higher degree of symmetry is undeniable, questions arise as to whether it was intentional or a by-product of the reduction process (cf. Nowell in Wynn 2002; McNabb et al. 2004; McPherron 2013). By working opposed edges in a repetitive, rulebased fashion, a certain level of symmetry is arguably unavoidable. Equally, the act of resharpening handaxes might accidentally enhance, rather than destroy, symmetry, as the need to maintain a good balance would require flakes to be removed from both faces and both edges (McPherron 2013). Tranchet removals, as seen at sites such as Boxgrove, do not, however, conform to this principle.

Those who accept symmetry as intentional often cannot agree on its significance. Lycett's (2008) conclusion, that handaxe symmetry was subject to natural selection for functional, adaptive or aesthetic reasons, brings us no closer to a solution; it does, however, suggest that symmetry was not a neutral by-product of knapping. A reductionist view might conclude that symmetry is linked to the basic functional properties of handaxes, but experimental analyses using Boxgrove-style handaxes for butchery concluded that symmetry had a negligible impact on the effectiveness of the cutting edges (Machin et al. 2007). One might also question whether the wide range of shapes, sizes and weight distributions all operated in the same fashion, or whether certain edge configurations (e.g. concave-edged 'ficrons') offered any functional advantages at all.

In a departure from the functional explanations of the 1980s and 1990s, current perspectives give handaxes more social meaning. Kohn and Mithen (1999) drew on Darwin's theory of sexual selection, interpreting symmetrical handaxes as a means of expressing male fitness and ensuring access to mates. Spikins (2012) linked them with altruistic and reciprocal behaviour, symmetrical handaxes serving as visual signals of an individual's trustworthiness and potential as an ally and team player. Gamble (1999) focused on the act of handaxe manufacture as a socially situated performance, with familiar rhythms and gestures used by individuals to express identity and mediate their place within the hominin group. The social performance, and the consequent endorphin rush (Gamble et al. 2014), is central, although it is difficult for us to see how the handaxes produced by this outpouring of skill and emotion could be mere epiphenomena. In either case, the context and location of such acts would have had implications for what precisely was played out (Porr 2005), and presumably, the extent to which an individual would 'bother' to elaborate a handaxe. Particular places may even have been associated with specific events and people, which triggered emotional responses. Similar notions were employed by McNabb (2012) in his 'visual display hypothesis', in which handaxes form part of a non-linguistic

(C) Antiquity Publications Ltd, 2018 
Table 1. Handaxe assemblages used in this study, divided according to the subgroups defined by Derek Roe (1968) and with proposed ages after Bridgland and White (2014).

\begin{tabular}{|c|c|c|c|c|c|}
\hline \multicolumn{3}{|c|}{ Pointed Tradition } & \multicolumn{3}{|c|}{ Ovate Tradition } \\
\hline Group I & Group II & Group III & Group V & Group VI & Group VI \\
\hline $\begin{array}{l}\text { Furze Platt } \\
\quad(\mathrm{n}=107) \\
\text { MIS } 9\end{array}$ & $\begin{array}{l}\text { Swanscombe } \\
\text { UMG } \\
(\mathrm{n}=110) \\
\text { MIS } 11\end{array}$ & $\begin{array}{c}\text { Wolvercote } \\
(\mathrm{n}=56) \\
\text { MIS } 9\end{array}$ & $\begin{array}{l}\text { Fordwich } \\
\qquad(\mathrm{n}=136) \\
\text { MIS } 15 \\
\text { or } 13\end{array}$ & $\begin{array}{l}\text { Elveden }(\mathrm{n}=64) \\
\quad \text { MIS } 11\end{array}$ & $\begin{array}{l}\text { Gaddesden } \\
\text { Row } \\
(\mathrm{n}=45) ?\end{array}$ \\
\hline $\begin{array}{l}\text { Cuxton } \\
\quad(\mathrm{n}=152) \\
\text { MIS } 9 / 8\end{array}$ & $\begin{array}{l}\text { Hoxne } \\
\text { Upper } \\
\text { Industry } \\
(\mathrm{n}=6) \\
\text { MIS } 11\end{array}$ & & & $\begin{array}{l}\text { Bowmans Lodge } \\
\quad(\mathrm{n}=29) \\
\text { MIS } 11\end{array}$ & $\begin{array}{l}\text { High Lodge } \\
(\mathrm{n}=66) \\
\text { MIS } 13\end{array}$ \\
\hline $\begin{array}{l}\text { Whitlingham } \\
\qquad(\mathrm{n}=130) ?\end{array}$ & $\begin{array}{c}\text { Dovercourt } \\
(\mathrm{n}=110) \\
\text { MIS } 11\end{array}$ & & & $\begin{array}{l}\text { Round Green } \\
\quad(\mathrm{n}=15) ?\end{array}$ & $\begin{array}{r}\text { Caddington } \\
(\mathrm{n}=29) ?\end{array}$ \\
\hline \multirow[t]{2}{*}{$\begin{array}{l}\text { Stoke } \\
\quad \begin{array}{l}\text { Newington } \\
(\mathrm{n}=70)\end{array} \\
\text { MIS } 9\end{array}$} & $\begin{array}{l}\text { Hitchin } \\
\quad(\mathrm{n}=63) \\
\text { MIS } 11\end{array}$ & & & $\begin{array}{l}\text { Holybourne } \\
\qquad(\mathrm{n}=16) ?\end{array}$ & $\begin{array}{l}\text { Boxgrove } \\
\text { Unit } 4 \\
(\mathrm{n}=78) \\
\text { MIS 13 }\end{array}$ \\
\hline & $\begin{array}{l}\text { Foxhall Road } \\
\quad(\mathrm{n}=57) \\
\text { MIS } 11\end{array}$ & & & $\begin{array}{l}\text { Swanscombe UL } \\
\quad(\mathrm{n}=19) \\
\text { MIS } 11 \\
\text { Wansunt }(\mathrm{n}=35) \\
\text { MIS } 11 \\
\text { Hoxne LI } \\
\quad(\mathrm{n}=12) \\
\text { MIS } 11\end{array}$ & \\
\hline
\end{tabular}

information-transfer system based around the body, and presumably contained clues about identity, self and the other.

Resonating through such interpretations is the idea that handaxes held aesthetic appeal for the makers and their observers, a sentiment expressed explicitly by Hodgson (2011) and Mithen (2008) — the latter declaring our modern appreciation of beautiful handaxes to be the echo of our Palaeolithic ancestors' emotions. Others go further, detecting in handaxe symmetry the beginnings of an artistic or symbolic sense, perhaps emerging over time from functional concerns (Le Tensorer 2006; Hodgson 2011).

\section{Materials and methods}

Twenty-two British Lower Palaeolithic assemblages were analysed, ranging in age from MIS 13 to MIS 8 ( 520-300ka) and comprising 1405 handaxes. These were selected because they represent stratigraphically secure groups recovered from excavations, or by unbiased collectors (Roe 1968; White 1998a). The assemblages are listed in Table 1, where they are divided into the shape-based subgroups identified by Roe (1968). These subgroups provide a robust morphological framework that, when interrogated at different scales 
Table 2. The Flip Test: asymmetry index, symmetry classes and descriptors.

\begin{tabular}{lcl}
\hline Symmetry class & Asymmetry index & Description \\
\hline & & \\
1 & $1.00-1.49$ & virtually perfect symmetry \\
2 & $1.50-2.99$ & very high symmetry \\
3 & $3.00-3.99$ & high symmetry \\
4 & $4.00-4.99$ & moderate symmetry \\
5 & $5.00-5.99$ & low symmetry \\
6 & $6.00+$ & very low symmetry \\
\hline
\end{tabular}

of analysis, correlate with factors such as raw material packages, localised technological practices (cultures) and time (e.g. White 1998a, 2006, 2015; Bridgland \& White 2014).

There is no standard method for measuring handaxe symmetry, with a number of quantitative (e.g. Saragusti et al. 1998, 2005) and qualitative (e.g. McNabb et al. 2004) tests proposed. To produce results that were repeatable, quantitative and easily understandable, we used the freely available Flip Test software (Hardaker \& Dunn 2005). The outputs of this program comprise a graphical representation, showing where an object deviates from perfect symmetry, and an index of asymmetry (AI), expressed as a number. The lower the value, the more symmetrical the handaxe. In practice, most handaxes show an AI between 1 and 7. Hardaker and Dunn (2005) divided handaxes into six handaxe symmetry classes (HSC) and provided a description for each class (Table 2); a graphical key to understanding these values is provided in Figure 1. Further details of the Flip Test and our metrical and technological observations are provided in the online supplementary material (OSM 1).

All sites were included in the regional analysis, but small sample size or missing data meant that some were omitted from the site-based analysis. Following Roe (1968), the handaxes from Foxhall Road were treated as a single assemblage, even though the sample is now known to be from two stratigraphically and typologically discrete groups (White $\&$ Plunkett 2004). This provided an opportunity to explore how mixing affected patterns of symmetry, and whether this could be detected at other sites (data for the individual Foxhall Road assemblages are provided in OSM 2).

\section{General results}

We started this research suspecting that highly symmetrical handaxes were probably rarer than 'popularly' thought, and also considering it probable that published images had helped to create a distorted picture by preferentially illustrating the more symmetrical examples. The distribution of AI for the British sample, however, displays a clear skew to the left, towards the highest grades of symmetry, with a long tail of more asymmetrical pieces (Figure 2). An unexpected 52.17 per cent of British handaxes have AI between 1.00 and 3.99-within HSC 1, 2 and 3, described qualitatively as having 'virtually perfect', 'very high' and 'high' symmetry, respectively. The number of handaxes in HSC 1 is low, only 1.4 per cent having AI values $<1.5$, but nevertheless, within a British context, the majority of handaxes are highly symmetrical or better.

(C) Antiquity Publications Ltd, 2018 


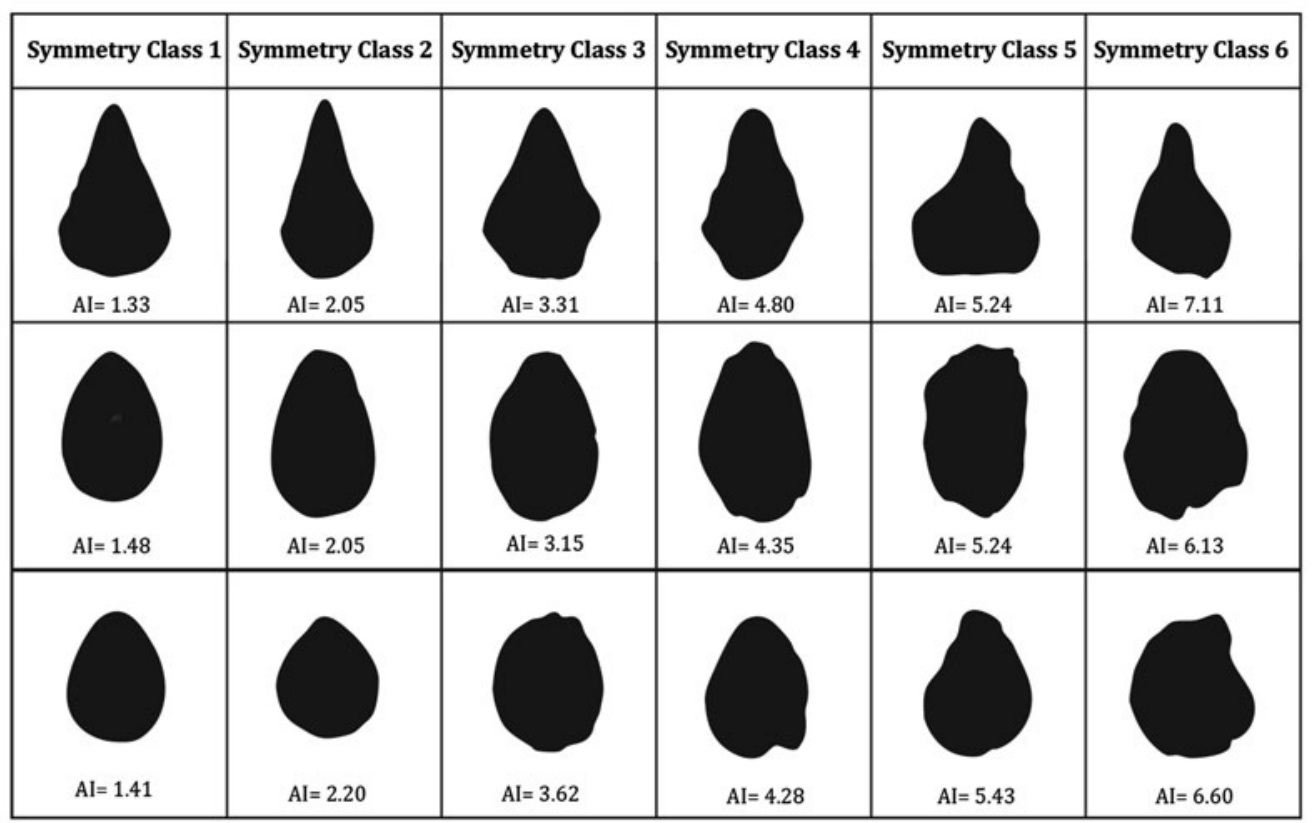

Figure 1. Graphical key to the asymmetry index (AI), showing handaxe silhouettes for a range of AI values. The silhouettes are of actual handaxes from Swanscombe (top), Boxgrove (middle) and Wansunt (bottom).

The British data show no evidence for increasing symmetry through time (Figure 3). The MIS 13 assemblage from Boxgrove is among the oldest yet the most symmetrical, while the MIS 9 assemblages from Furze Platt and Stoke Newington are the least symmetrical. In fact, the data split not by date but by Roe's handaxe groups (pointed subgroups I, II, III and $\mathrm{V}$ all have mean $\mathrm{AI}>4$; ovate subgroups VI and VII have mean AI $<4$ ), within which 'top level' planform biases have been argued to relate to differing raw material packages and historically developed technological responses (White 1998a). Sites in Roe's groups VI and VII also show a tighter range of symmetry than those in groups I, II and V.

\section{Site and group level symmetry}

At the site level, most assemblages show a left-skewed distribution (Figure 4, OSM 3), with 15 out of 20 containing $>50$ per cent of handaxes in HSC 1, 2 or 3. Only Furze Platt (28 per cent in classes 1-3), Stoke Newington (38 per cent), Cuxton (26 per cent), Swanscombe Upper Middle Gravel (UMG, 37 per cent) and Fordwich (45 per cent) show a preponderance of handaxes with moderate to very low symmetry, a set that subsumes most of Roe's subgroup I, subgroup V and one example from subgroup II. The basic division in the data is again between Roe's two morphological traditions, with ovate-dominated assemblages containing higher frequencies of handaxes in HSC 1-3 than point-dominated assemblages. 


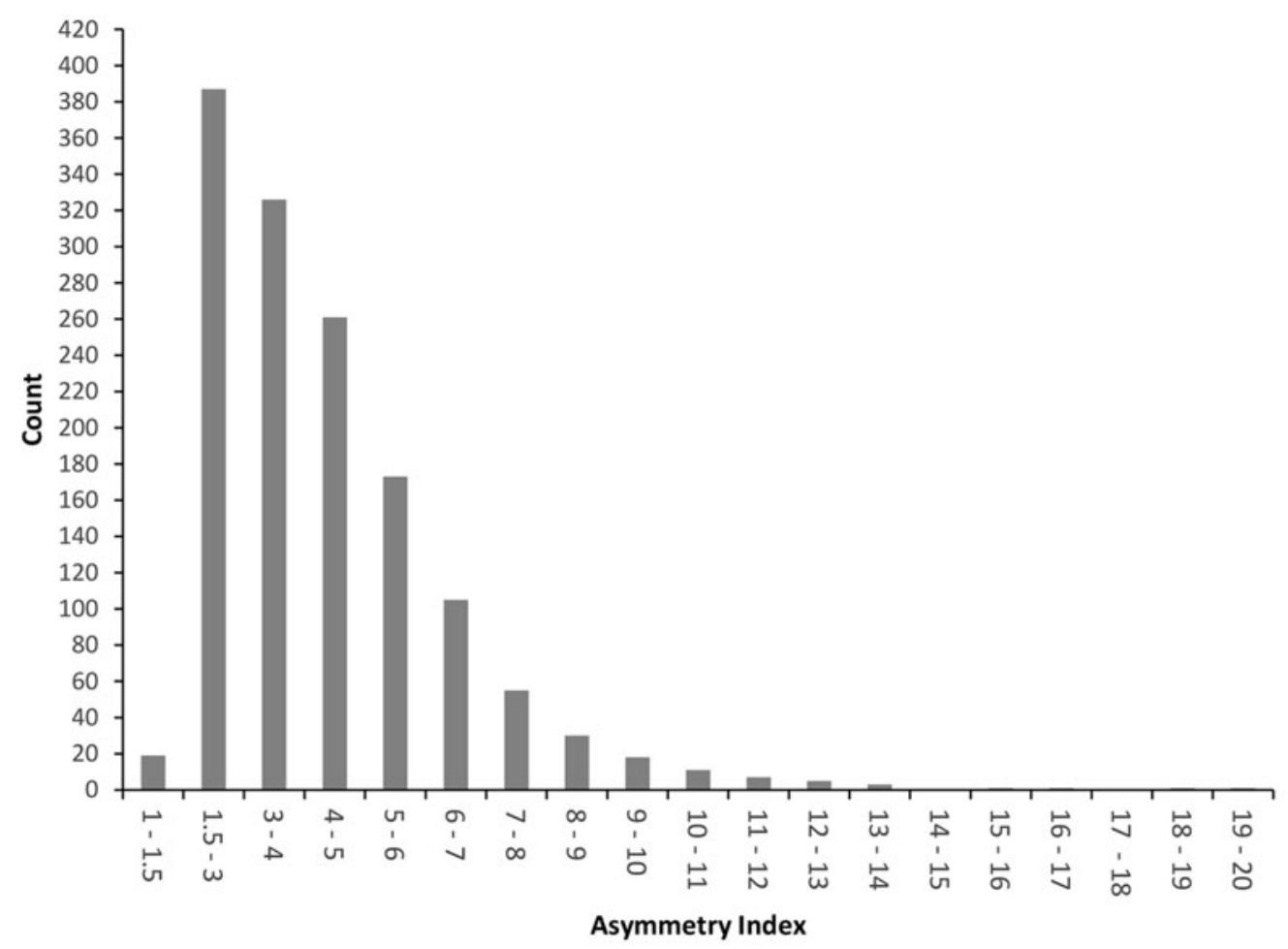

Figure 2. Distribution of asymmetry index values for the entire British sample.

The proposed relationship between Roe's groups, raw material packages and knapping methods (White 1998a) is important in understanding this pattern. Sites in subgroups VI and VII tend to be found in situations where large nodules or flakes were used, allowing higher levels of shaping and, consequently, greater levels of symmetry. The other subgroups are usually found where smaller river cobbles were used, the form of the blanks being better suited to less intensively worked pointed handaxes with long tips, poorly worked butts and high cortex retention (Ashton \& McNabb 1994; White 1998a). This inevitably affected the levels of symmetry imposed, although it is critical to remember that even in these resource contexts, hominins still took the opportunity to mirror natural margins and imposed very high levels of symmetry when they could, as seen, for example, in the remarkable Furze Platt Giant $(\mathrm{AI}=1.76)$.

Linear regression analyses for symmetry against measures of shape and knapping intensity, for sites with $>20$ handaxes, are presented in OSM 3. Symmetry frequently shows a significant but weak correlation with scar count, edge working and cortex percentageattributes regarded as indicators of knapping intensity, the degree to which the original stone blank was modified in one or more episodes of working. A significant weak to moderate correlation between symmetry and scar count is found at 84 per cent of sites from all subgroups, showing that, regardless of shape, more intensively worked handaxes tend to be more symmetrical. A significant correlation between edge working and symmetry is evident (C) Antiquity Publications Ltd, 2018 


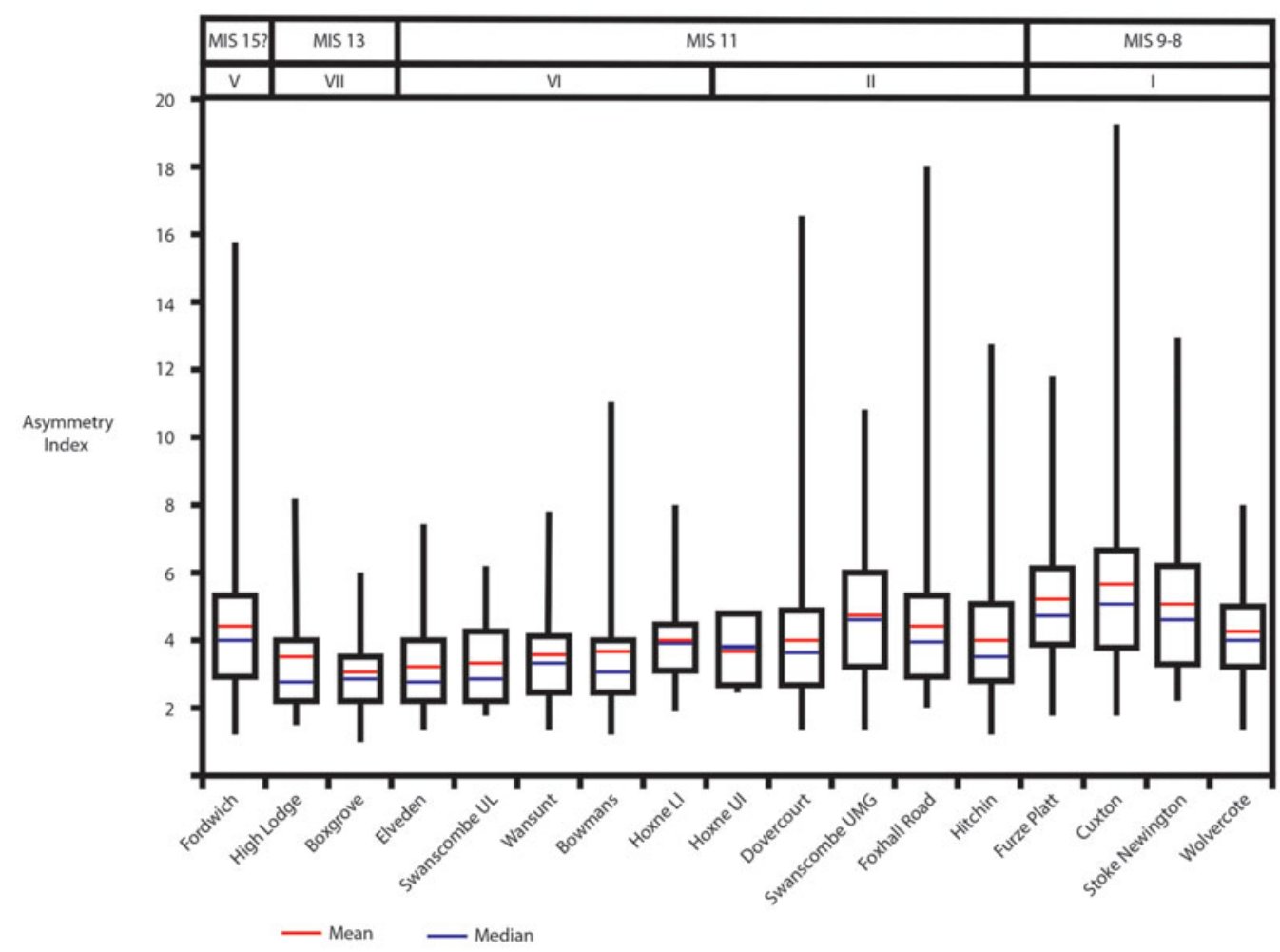

Figure 3. Boxplots showing the mean asymmetry index and range of variation in British handaxes. The sites are organised by age, with the oldest sites on the left (top row). Roe's subgroup designations are given in the second row. There is no correlation between age and symmetry in the Middle Pleistocene.

at 10 sites (out of 18), eight of which belong to the point-dominated groups. There is no relationship between symmetry and edge working in Roe's ovate tradition, other than at Round Green and Gaddesden Row, both of which contained isolated but extreme outliers well beyond the main distribution in either site $(\mathrm{AI}=7.8$ and $\mathrm{AI}=9.8$, respectively; see revised figures in OSM $3 \& 4$ ). Cortex retention similarly correlates with symmetry in point-dominated groups, but not in ovate-dominated ones.

These patterns again reflect different technological approaches used in the manufacture of different handaxes. As demonstrated by White (1998a), for handaxes in subgroups VI and VII, $360^{\circ}$ working is the norm, with most having a cutting edge around their entire circumference and very little cortex, regardless of final shape or symmetry. In the pointdominated assemblages, the knapper often used a more linear knapping style, concentrating on an extended tip and leaving a shorter butt, the latter frequently retaining cortical or natural edges with no human shaping at all. Pointed handaxes thus show a wider diversity of edge working and cortex retention. Simply put, the more a knapper transformed the blank, the more symmetry they were able to impose upon it. The absence of any relationship between cortex and symmetry in Roe's ovate tradition (OSM 3) results from the fact that

(C) Antiquity Publications Ltd, 2018 

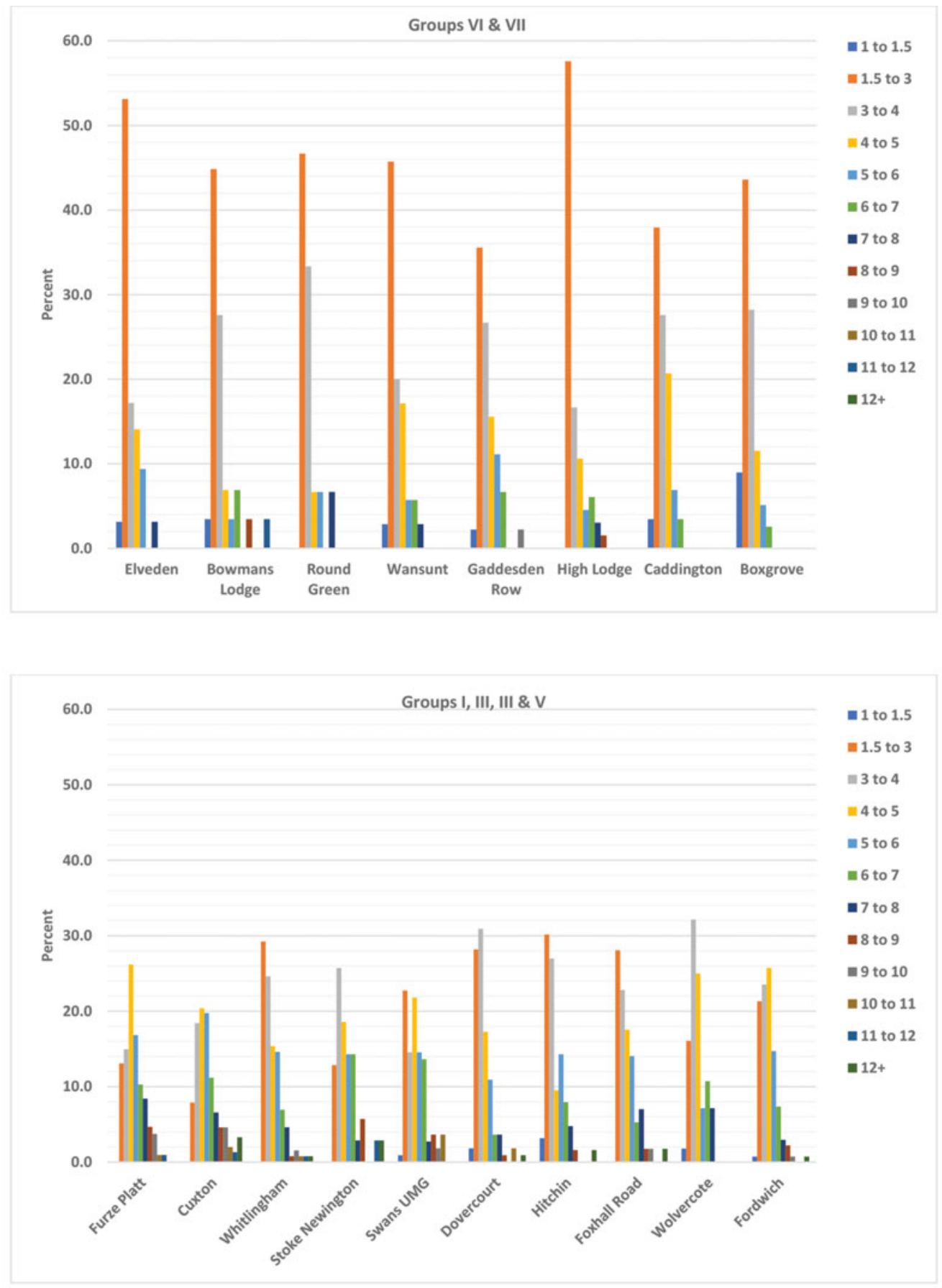

Figure 4. Distribution of asymmetry index values for British handaxe assemblages.

(C) Antiquity Publications Ltd, 2018 


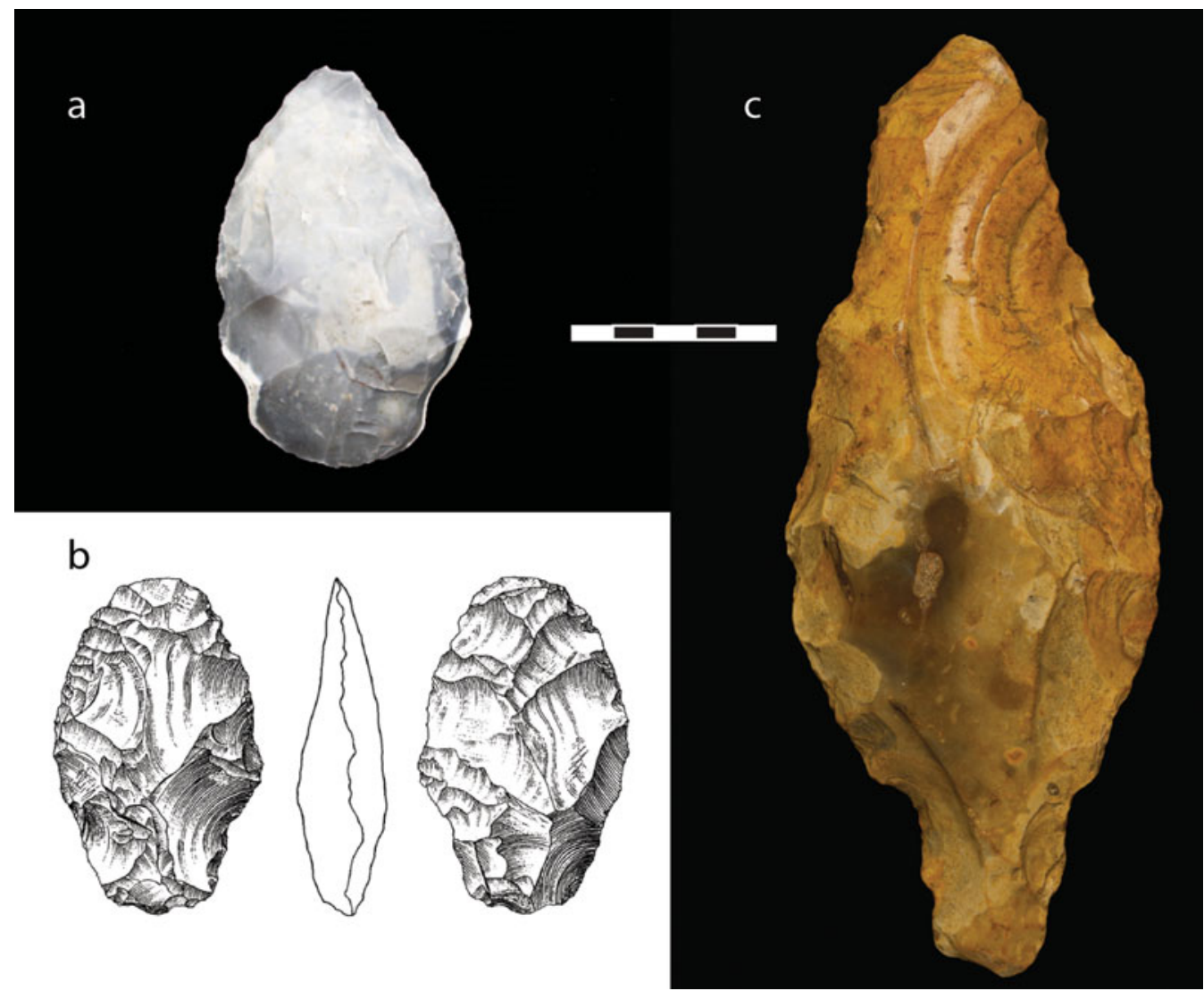

Figure 5. Signs of deliberate symmetry: a) handaxe from Boxgrove $Q 1 / B$, showing the incorporation of a naturally symmetrical boss on the nodule into the design of a symmetrical handaxe (after Pope et al. 2006); b) handaxe from Elveden area II showing deliberate mirroring of knapped edges using delicate trimming removals, creating a shouldered butt (after Ashton \& White 2003); c) handaxe from Swanscombe Middle Gravels showing deliberate mirroring of the margins, and of the tip and butt (photograph: Jeff Veitch).

most handaxes in these sites possess zero or $<5$ per cent residual cortex. High levels of working are thus a constant, around which symmetry fluctuates.

This does not mean that symmetry is an accidental and progressive result of the reduction process. The fact that ovate assemblages show wide variation in symmetry, despite consistently high reduction intensity, suggests that symmetry was not a side effect, but a variably applied design feature. Furthermore, low levels of reduction in pointed assemblages do not always result in poor symmetry. In many cases-particularly at Dovercourt, Stoke Newington, Wolvercote and Whitlingham—symmetry has been achieved despite low levels of working (particularly at the butt; OSM 5) by the advantageous use of natural symmetry, or by the use of limited amounts of working to mirror natural edges or other irregularities (Figure 5a). It seems inconceivable that this could be accidental in every instance, and the selection of symmetrical nodules and mirroring of natural surfaces support the notion that hominins were mindful of symmetry. 
Six sites show a significant correlation between symmetry and refinement, with a weak tendency for more refined handaxes to be more symmetrical. Refinement may relate to knapping intensity, skill or nothing more than the thickness of the original nodule, and in many cases, a significant result is caused by outliers (OSM 4). At all other sites, refinement does not correlate with symmetry. Relatively thick handaxes can be remarkably symmetrical, and vice versa, again suggesting that increased symmetry is not a by-product of progressive bifacial knapping.

With the exception of Wolvercote and Swanscombe UMG, no sites showed any significant correlation between symmetry and any other measure of outline shape (OSM $3 \& 4$ ). The patterns at Wolvercote and Swanscombe UMG reveal a weak to very weak tendency for more pointed handaxes to be more symmetrical, a trend not seen at other sites, and which may relate to special attention at the tip. Within most assemblages, then, handaxes tend to be symmetrical, regardless of actual shape. The association between reduction intensity, symmetry and intent is explored further in OSM 5 and 6 using butt working and tip working as proxies. The results from Foxhall Road, Hitchin and Wolvercote show a number of deviations from the general patterns for the whole sample, or for the point-dominated subgroups, each of which can be understood in the terms described in OSM 3 and 7.

\section{Discussion}

Bilateral symmetry in handaxes is not an esoteric phenomenon, but one with significant implications for hominin cognitive and socio-behavioural evolution. It is therefore important that we properly understand its frequency and nature, and the reasons for variation. Our results show that symmetry is highly expressed in the Late Middle Pleistocene record, with hominins apparently maximising symmetry wherever possible and desirable, 'doing their best' in the face of sometimes recalcitrant raw materials and personal factors such as skill and experience. In cases where cobbles and pebbles affected the knappers' technological choices and palette of forms, hominins often worked with this by selecting blanks with a higher degree of natural symmetry and incorporating this into the design of the handaxe. Calculated blank selection is thus a critical element of human technological behaviour and decision-making concerning handaxe form.

Despite the link between reduction intensity and symmetry, we do not interpret our data as supporting a purely accidental or functional explanation for symmetry (cf. Machin et al. 2007; contra White 1998a). It is still uncertain whether functional considerations during resharpening preserved or destroyed symmetry (McPherron 2013), or, conversely, whether handaxes were consistently resharpened at all. When they were, in the form of tranchet removals, there was little concern for symmetry (OSM 8). Instead, we interpret symmetry as a deliberate and significant part of Acheulean social technology, with greater levels of reduction simply allowing hominins to bring out higher levels of symmetry. Whether this acted as a social glue, a silica information-highway, a marque of trustworthiness or as an indicator of male fitness, we currently leave to others, but suggest that an even more fundamental principle has been overlooked—reward and pleasure.

(C) Antiquity Publications Ltd, 2018 
Palaeolithic human emotions, motivations and intentions are difficult to reconstruct with confidence or approval. All mammals, however, have reward systems associated with dopamine neurons in their brains that, when triggered, induce a range of positive feelings and emotions (Schultz 2015). In the human brain, the key areas are the midbrain dopamine neurons, striatum, amygdala and orbitofrontal cortex; reward signals are also found in components of the basal ganglia and cerebral cortex, and are often associated with sensory or motor activity (Schultz 2015: 861). Rewards play a vital evolutionary role, providing animals with the basic motivations to survive and reproduce, and having the potential to foster learning, promote decision-making and give pleasure. Pleasure is pivotal to rewards, being both a major reward function and the hallmark of a reward (Schultz 2015: 859). Reward stimuli are classed as either primary—directly pertaining to survival and reproductive activities—or non-primary—rewards not directly related to subsistence or mating, but which serve to enhance them, even if their functions are not evoked at any precise moment (Schultz 2015). Non-primary rewards come in many forms including physical (money, valued objects), social (friends, alliances, events), sensory (pleasant music, a radiant sunset) and non-physical (jokes, relaxation). They include the little pleasures in life, and they can be intrinsic, pleasurable simply for their own sake. Whatever form they take, rewards combine sensory components (which can be sensed), salient components (which get attention) and value components (which reflect internalised, individual and subjective preferences that set the conditions for what different people find rewarding; Schultz 2015: 856). So, while all rewards affect the body through sensory systems, there is no single value or property that defines a reward. Rather, rewards are defined by subjective preferences (individual/cultural, private/shared) and the behavioural responses that they invoke. Critically, rewards are self-reinforcing-humans and animals crave rewards and seek them out because they give pleasure - and they in turn have the potential to promote learning, decision-making and positive emotions.

Lower Palaeolithic material culture undoubtedly provided many new reward opportunities. It is easy to imagine the primary rewards associated with fire and hearth, warm attire, hunting weapons or using a handaxe to butcher a carcass. In the context of a social technology, however, handaxes were more than just supports for sharp edges, but physically resonated with social value and non-primary rewards. Twisted edges, for example, offer no apparent practical enhancement, but dramatically transform the appearance and feel of the object while retaining bilateral symmetry. At Foxhall Road this design feature was imposed in an almost identical fashion on three almost identical handaxes, found lying together in a small cluster (White \& Plunkett 2004). Further examples where the sensory impact of an object seems to have outweighed other considerations include the Furze Platt Giant, the fossil inclusions from Swanscombe and West Toft, WenbanSmith's (2004) 'flamboyant' ficron from Cuxton, Frere's acutely pointed 'weapon' from Hoxne, the perfectly crafted 'toys' and 'sickle' from Foxhall Road, and numerous other instances of deliberate shaping and mirroring. The sickle aside, these objects are also highly symmetrical—elaborately so in some cases—just like many handaxes.

We will never know precisely why these objects were created and what social message they transmitted, but we may assume that their makers derived pleasure from crafting them. We acknowledge that they could be dismissed as aberrations, forms that seem 
extravagant, aesthetically pleasing, time-consuming and functionally illogical to us, but which are, in fact, just statistically insignificant points on a wide continuum-little more than hominin personality quirks in a humdrum world. Indeed, they rarely deviate far from the 'essential' handaxe form. But this is a critical point in our argument. Within a pleasure-reward system, these excursions represent a 'peak shift effect' (Ramachandran \& Hirstein 1999: 18): exaggerated expressions of an already rewarding behaviour aimed at eliciting even greater rewards. Thus, in relating the pleasure-reward system to handaxes, we are not thinking only of occasional highs derived from flamboyant rarities, but to the routine practice of making a nice handaxe, any nice handaxe, and the intrinsic pleasure that involved.

For hominins, the handaxe experience was sensory. They saw them, felt them, heard the ring of knapping and smelled the 'burnt ozone' when making them-indeed, they affected almost all sensory systems except taste, although their role in butchery rendered that an anticipatory reward (cf. Balodis \& Potenza 2015). As reward stimuli, handaxes have salient and sensory components, and capture critical value components- the intersubjective preferences derived from being part of a hominin society, from being in their world. The experience was one of life-long learning: playing with technology as infants and learning to make handaxes as children; later experimenting with social norms and perfecting motor skills; ultimately mastering shape and heterogeneous materials to produce signature handaxes consistently. All of these stages had their own pleasures and rewards, mediated through a continuous process of operant learning (active learning in which an individual's own actions generate reward and provide positive reinforcement; Schultz 2015: 854), which reinforced engagement with social technology. The more a hominin could master technology, the greater that pleasure. (The definition of mastery subject to personal and socially derived value components and skill levels that no doubt changed throughout an individual's lifetime.) We would argue, however, that much of the time it involved a technically refined and symmetrical handaxe, the precise shape of which depended on historically mediated local and temporal variations.

This does not deny the obvious associations with primary, alimentary rewards, and has no requirement for Acheulean hominins to have had modern language or cognition, a full theory of mind (McNabb 2012), or a hard-wired biface instinct (Corbey et al. 2016). Our theory is unashamedly post-hoc in as far as it pertains to symmetry. But other elements of the Acheulean record may also be viewed in this light: the abundance of handaxes in single locations; the apparent obsessive nature in which some handaxes and flake tools have been worked; functionally neutral (or negative) variations, such as twists and ficrons; the long duration and 'variable sameness' of the Acheulean. Different value-components and contexts for action also meant that some hominins or hominin societies may not have found handaxe manufacture as rewarding and pleasurable as others, at least not all of the time. That symmetry and refined working has value to modern archaeologists is also clear in the illustration biases evident in some archaeological texts (see OSM 9). Whether it is equally relevant over three continents and 1.4 million years remains to be seen, although our preliminary results on published data from Olduvai suggest a dramatic increase in the frequency of high to very high symmetry in Bed IV, dating to approximately $1 \mathrm{ma}$. It may have emerged from basic technological and functional concerns (cf. McNabb 2004;

(C) Antiquity Publications Ltd, 2018 
Hodgson 2011), but by $1 \mathrm{ma}$, symmetry and shape had assumed a greater prominence and delivered new rewards in the lives of Acheulean hominins.

Knapping and making may have had other physiological advantages and reinforcements, such as the release of endorphins, analgesics that also help to reinforce social bonds among conspecifics (Gamble et al. 2014). Studies of art therapy have similarly demonstrated a significant reduction in salivary cortisol (a glucocorticoid hormone used as a measure of physiological stress) as a result of making visual art, regardless of age, level of experience or skill; and yet with age and experience might also come additional pressure to perform above the norm (Kaimal et al. 2016). Indeed, when things went wrong, quite different emotions, such as anger and frustration, were expressed in a way that we can easily identify in the archaeological record. At Caddington, for example, conjoining parts of handaxes that 'end-shocked' during manufacture were sometimes found in two locations - the part that dropped to the floor remaining with the flakes from its creation, and the part that had temporarily remained in the knapper's hand hurled several metres away in frustration (Smith 1894; Sampson 1978). According to Sampson's analysis (1978: 146-48), this person was a novice; when another more experienced knapper made the same mistake, they calmly let the pieces fall to the ground.

\section{Conclusion}

We have demonstrated that the majority of handaxes from 22 British Middle Pleistocene assemblages can be classed as highly symmetrical or better. We consider this a deliberate choice on the part of the makers, with levels of symmetry affected by skill and experience, approaches to raw material and the social context of the action. We suggest that lithic technology in general, and handaxes in particular, were part of a pleasure-reward system linked to dopamine-releasing neurons in the brain. These rewards/pleasures came in different forms, including alimentary rewards for foods processed using tools and the socialsexual rewards possibly involved in tool-display behaviour. Such considerations, however, provide only part of the answer. For us, hominins derived intrinsic pleasure from creating a handaxe: making handaxes made Acheulean hominins happy, especially when they turned out well or carried a personal twist. One particularly pleasing property was symmetry, part of an ancient neural network. It is the same chemicals and same immersion in material culture that make us appreciate the same qualities (cf. Mithen 2008), a pleasure principle that appears pleasingly time-transferable.

\section{Acknowledgements}

The authors would like to thank Thomas Wynn and Rob Hosfield for their valuable and highly encouraging comments on the original submitted draft of this paper.

\section{Supplementary material}

To view supplementary material for this article, please visit https://doi.org/10.15184/aqy. 2018.35 


\section{References}

Ashton, N.M. \& J. McNabi. 1994. Bifaces in perspective, in N.M. Ashton \& A. David (ed.) Stories in stones: 182-91. London: Lithic Studies Society.

Ashton, N.M. \& M.J. White. 2003. Bifaces and raw materials: flexible flaking in the British Earlier Palaeolithic, in M. Soressi \& H. Dibble (ed.) From prehistoric bifaces to human behaviour: 109-23. Philadelphia: University of Pennsylvania Museum of Archaeology and Anthropology.

Balodis, I.M. \& M.N. Potenza. 2015. Anticipatory reward processing in addicted populations: a focus on the monetary incentive delay task. Biological Psychiatry 77: 434-44.

https://doi.org/10.1016/j.biopsych.2014.08.020

Beyene, Y., S. Кatoh, G. WoldeGabriel, W.K. Hart, K. Uto, M. Sudo, M. Kondo, M. Hyodo, P.R. Renne, G. Suwa \& B. Asfaw. 2013. The characteristics and chronology of the earliest Acheulean at Konso, Ethiopia. Proceedings of the National Academy of Sciences of the USA 110: 1584-91. https://doi.org/10.1073/pnas. 1221285110

Bridgland, D.R. \& M.J. White. 2014. Fluvial archives as a framework for the Lower and Middle Palaeolithic: patterns of British artefact distribution and potential chronological implications. Boreas 43: 543-55. https://doi.org/10.1111/bor.12059

Cole, J. 2015. Examining the presence of symmetry within Acheulean handaxes: a case study in the British Palaeolithic. Cambridge Archaeological Journal 24: 713-32. https://doi.org/10.1017/S0959774315000141

Corbey, R., A. Jagich, K. Vaesen \& M. Collard. 2016. The Acheulean handaxe: more like a bird's song than a Beatles' tune? Evolutionary Anthropology 25: 6-19. https://doi.org/10.1002/evan.21467

Gamble, C.S. 1999. The Palaeolithic societies of Europe. Cambridge: Cambridge University Press.

Gamble, C.S., J. Gowlett \& R. Dunbar. 2014. Thinking big. London: Thames \& Hudson.

Hardaker, T. \& S. Dunn. 2005. The Flip Test-a new statistical measure for quantifying symmetry in stone tools. Antiquity Project Gallery 79(306). Available at: http://www.antiquity.ac.uk/projgall/hardaker306/ (accessed 27 February 2018).

Hodgson, D. 2009. Evolution of the visual cortex and the emergence of symmetry in the Acheulean techno-complex. Palevol 8: 93-97. https://doi.org/10.1016/j.crpv.2008.10.009
- 2011. The first appearance of symmetry in the human lineage: where perception meets art. Symmetry 3: 37-55. https://doi.org/10.3390/sym3010037

- 2015. The symmetry of Acheulean handaxes and cognitive evolution. Journal of Archaeological Science: Reports 2: 204-208.

IsAAC, G. 1977. Olorgesailie: archaeological studies of a Middle Pleistocene lake basin in Kenya. Chicago (IL): University of Chicago Press.

Kaimal, G., K. Ray \& R. Muniz. 2016. Reduction of cortisol levels and participants' responses following art making. Art Therapy 33: 74-80. https://doi.org/10.1080/07421656.2016.1166832

Kohn, M. \& S. Mithen. 1999. Handaxes: products of sexual selection? Antiquity 73: 518-26. https://doi.org/10.1017/S0003598X00065078

Le Tensorer, J.M. 2006. Les cultures acheuléenes et la question de l'emergence de la pensée symbolique che Homo erectus à partir des données relatives à la form symétrique et harmonique des bifaces. Palevol 5: 127-35. https://doi.org/10.1016/j.crpv.2005.12.003

LyCETT, S. 2008. Acheulean variation and selection: does handaxe symmetry fit neutral expectations. Journal of Archaeological Science 35: 2640-48. https://doi.org/10.1016/j.jas.2008.05.002

Machin, A.J., R.T. Hosfield \& S.J. Mithen. 2007. Why are some handaxes symmetrical? Testing the influence of handaxe morphology on butchery effectiveness. Journal of Archaeological Science 34: 883-93. https://doi.org/10.1016/j.jas.2006.09.008

McNABB, J. 2012. The importance of conveying visual information in Acheulean society: the background to the visual display hypothesis. Human Origins 1: $1-23$.

McNabb, J., F. Binyon \& L. Hazelwood. 2004. The large cutting tools from the South African Acheulean and the question of social traditions. Current Anthropology 45: 653-68. https://doi.org/10.1086/423973

McPherron, S. 1994. A reduction model for variability in Acheulian biface morphology. Unpublished PhD dissertation, University of Pennsylvania.

- 2013. Perspectives on stone tools and cognition in the Early Paleolithic record, in C.M. Sanz, J. Call \& C. Boesch (ed.) Tool use in animals: cognition and ecology: 286-309. Cambridge: Cambridge University Press.

Mithen, S. 2008. 'Whatever turns you on': a response to Anna Machin. Antiquity 82: 761-69. https://doi.org/10.1017/S0003598X00097374 


\section{Symmetry is its own reward}

Pope, M., K. Russel \& K. Watson. 2006. Biface form and structured behaviour in the Acheulean. Lithics 27: 44-57.

Porr, M.K. 2005. The making of the biface and the making of the individual, in C. Gamble \& M. Porr (ed.) The hominin individual in context: archaeological investigations of Lower and Middle Palaeolithic landscapes, locales and artefacts: 68-80. London: Routledge.

Ramachandran, V. \& W. Hirstein. 1999. The science of art: a neurological theory of aesthetic experience. Journal of Consciousness Studies 6: 15-51.

Roe, D.A. 1968. British Lower and Middle Palaeolithic handaxe groups. Proceedings of the Prehistoric Society 34: $1-82$. https://doi.org/10.1017/S0079497X00013840

Sampson, C.G. (ed.). 1978. Paleoecology and archaeology of an Acheulian site at Caddington, England. Dallas (TX): Southern Methodist University.

Saragusti, I., I. Sharon, O. Katzenelson \& D. Avnir. 1998. Quantitative analysis of the symmetry of artefacts: Lower Palaeolithic handaxes. Journal of Archaeological Science 25: 817-25. https://doi.org/10.1006/jasc.1997.0265

Saragusti, I., A. Karasik, I. Sharon \& U. Smilansky. 2005. Quantitative analysis of shape attributes based on contours and section profiles in artefact analysis. Journal of Archaeological Science 32: 841-53. https://doi.org/10.1016/j.jas.2005.01.002

Schultz, W. 2015. Neuronal reward and decision signals: from theories to data. Physiological Reviews 95: 853-951. https://doi.org/10.1152/physrev.00023.2014

Sinclair, A. \& J. McNabi. 2005. All in a day's work: Middle Pleistocene individuals, materiality and the lifespace at Makapansgat, South Africa, in C. Gamble \& M. Porr (ed.) The hominin individual in context: archaeological investigations of Lower and Middle Palaeolithic landscapes, locales and artefacts: 176-96. London: Routledge.

Sмiтн, W.G. 1894. Man the primeval savage. London: Stanford.
SpIKINs, P. 2012. Goodwill hunting? Debates over the 'meaning' of Lower Palaeolithic handaxe form revisited. World Archaeology 44: 378-92. https://doi.org/10.1080/00438243.2012.725889

UNDERHILl, D. 2007. Subjectivity inherent in by-eye judgements and the large cutting tools at the Cave of Hearths, Limpopo Province, South Africa. Papers from the Institute of Archaeology 18: 1-12. https://doi.org/10.5334/pia.305

Wenban-Smith, F. 2004. Handaxe typology and the Lower Palaeolithic cultural development: ficrons, cleavers and two giant handaxes from Cuxton. Lithics 25: 11-21.

White, M.J. 1998a. On the significance of Acheulean biface variability in southern Britain. Proceedings of the Prehistoric Society 64: 15-44. https://doi.org/10.1017/S0079497X00002164

- 1998b. Twisted ovate bifaces in the British Lower Palaeolithic: some observations and implications, in A. Ashton, F. Healy \& P. Pettitt (ed.) Stone Age archaeology: essays in honour of John Wymer: 98-104. Oxford: Oxbow.

- 2006. Axeing cleavers: reflections on broad-tipped large cutting tools in the British Lower and Middle Palaeolithic, in N. Goren-Inbar \& G. Sharon (ed.) Axe age: Acheulean toolmaking, from quarry to discard: 365-86. Jerusalem: Equinox.

- 2015. 'Dancing to the rhythms of the biotidal zone': settlement history and culture history in Middle Pleistocene Britain, in F. Coward, R. Hosfield, M. Pope \& F. Wenban-Smith (ed.) Settlement, society and cognition in human evolution: 154-73. Cambridge: Cambridge University Press. https://doi.org/10.1017/CBO9781139208697

White, M.J. \& S.J. Plunkett. 2004. Miss Layard excavates: a Palaeolithic site at Foxhall Road, Ipswich, 1903-1905. Liverpool: WASP.

Wynn, T. 1995. Handaxe enigmas. World Archaeology 27: 10-24. https://doi.org/10.1080/00438243.1995.9980290

- 2002. Archaeology and cognitive evolution. Behavioural and Brain Sciences 25: 389-437. https://doi.org/10.1080/00438243.1995.9980290

Received: 6 February 2017; Accepted: 28 February 2018; Revised: 5 May 2017

(C) Antiquity Publications Ltd, 2018 